DOI:

УДК 621.09

В.С. Коротков, к.т.н., доцент, kvs55dn@gmail.com

А.А. Шумейко, д.т.н., професор, shumeiko_a@ukr.net

Дніпровський державний технічний університет, м. Кам'янське

\title{
МОДЕЛЮВАННЯ ФОРМОУТВОРЕННЯ ПОВЕРХОНЬ РІЗАЛЬНИМ ІНСТРУМЕНТОМ НА ВЕРСТАТАХ 3 ЧПК
}

В статті розглянутий варіант побудови математичного апарату для отримання координат поверхонь деталей при їх переміщенні у просторі. Рішення таких задач доцільно при розрахунках траєкторій руху формоутворюючих інструментів при обробиі на верстатах $з$ ЧПК.

Ключові слова: координати поверхонь деталей; інструмент; верстат з ЧПК.

In the article the variant of construction of the mathematical apparatus for obtaining coordinates of surfaces of details at their moving in space is considered. The solution of such problems is expedient when calculating the trajectories of motion forming tools when processing on CNC machines.

Keywords: coordinates of surfaces of details; tool; CNC machine.

\section{Постановка проблеми}

На стадії підготовки керуючої програми (КП) обробки різанням на верстатах з ЧПК розраховують траєкторію руху інструменту для забезпечення ефективного формоутворення поверхонь деталей у відповідності з вимогами технології $[1,2,3]$. Обробка поверхонь складної форми 3 високою точністю ускладнює рішення багатьох задач щодо вибору послідовності виконання операцій, розподілення припусків по технологічним переходам, визначення режимів обробки і т.ін. Пошук ефективних рішень передбачає розгляд і порівняння багатьох можливих варіантів формоутворення поверхонь і визначення кращого по певним критеріям $[4,5,6]$. Природньо, що такі роботи доцільно виконувати на етапі підготовки КП з можливістю моделювання процесів при використанні засобів автоматизації.

В процесі металообробки по КП на верстатах з ЧПК виникають похибки, на формування яких впливають дії багатьох чинників, передбачити дію яких дуже важко. Тому на практиці часто виникає потреба корекції траєкторії руху інструменту для усунення недопустимих відхилень розмірів [7]. Схожі задачі вирішують при внесенні змін у розміри деталей, що оброблюються, чи зміні технологічних вимог.

\section{Формулювання мети роботи}

Ураховуючи специфіку робіт по підготовці КП і, в особливості, розрахунків траєкторій руху інструментів, виникає потреба в розробці ефективних методів моделювання процесів формоутворення поверхонь деталей. Зокрема необхідно розробити методи і прийоми визначення координат поверхонь деталей при формоутворенні різальним інструментом різної форми і розмірів. Методи повинні бути універсальні і придатні для впровадження в засобах автоматизації, які використовують на стадії підготовки керуючих програм для верстатів з ЧПК. Аналогічні методи можуть бути використані безпосередньо в системах ЧПК верстатами, що значно розширює можливості обладнання в умовах виробництва.

\section{Виклад основного матеріалу}

Для математичного опису формоутворення, зокрема складних поверхонь, зазвичай застосовують метод перетворення координат, що дозволяє за допомогою матриць і векторів четвертого порядку отримувати і аналізувати рівняння поверхонь у трьохмірному просторі. Особливість цього методу полягає у тому, що будь-які перетворення координат можуть бути записані за допомогою математичної операції множення матриць. Згідно рівнянню теорії формоутворення [5], зв'язок між початковими і кінцевими координатами інструменту при обробці деталі може бути записаний у вигляді: 


$$
r_{0}=A \cdot r_{l},
$$

де $r_{0}$ - вихідні координати інструменту; $r_{l}$ - координати інструменту в процесі переміщення; $A$ - добуток матриць виду

$$
A_{x}=\left(\begin{array}{llll}
1 & 0 & 0 & a \\
0 & 1 & 0 & 0 \\
0 & 0 & 1 & 0 \\
0 & 0 & 0 & 1
\end{array}\right), \quad A_{y}=\left(\begin{array}{cccc}
1 & 0 & 0 & 0 \\
0 & 1 & 0 & b \\
0 & 0 & 1 & 0 \\
0 & 0 & 0 & 1
\end{array}\right), \quad A_{z}=\left(\begin{array}{cccc}
1 & 0 & 0 & 0 \\
0 & 1 & 0 & 0 \\
0 & 0 & 1 & c \\
0 & 0 & 0 & 1
\end{array}\right),
$$

$$
A_{ц}=\left(\begin{array}{cccc}
1 & 0 & 0 & 0 \\
0 & \cos ц & -\sin ц & 0 \\
0 & \sin ц & \cos ц & 0 \\
0 & 0 & 0 & 1
\end{array}\right), A_{\text {ш }}=\left(\begin{array}{cccc}
\cos ш & 0 & \sin ш & 0 \\
0 & 1 & 0 & 0 \\
-\sin ш & 0 & \cos ш & 0 \\
0 & 0 & 0 & 1
\end{array}\right) \quad A_{\text {и }}=\left(\begin{array}{cccc}
\cos \text { и } & -\sin \text { и } & 0 & 0 \\
\sin \text { и } & \cos \text { и } & 0 & 0 \\
0 & 0 & 1 & 0 \\
0 & 0 & 0 & 1
\end{array}\right) .
$$

Матриці $A_{x}, A_{y}, A_{z}$ - моделюють поступальний рух вздовж осей $X, Y, Z$ на величину $a, b$ і $c$ відповідно, а матриці $A_{\text {ц }}, A_{\text {ш }} A_{\text {и }}$ - обертання навколо цих осей (рис. 1$)$.

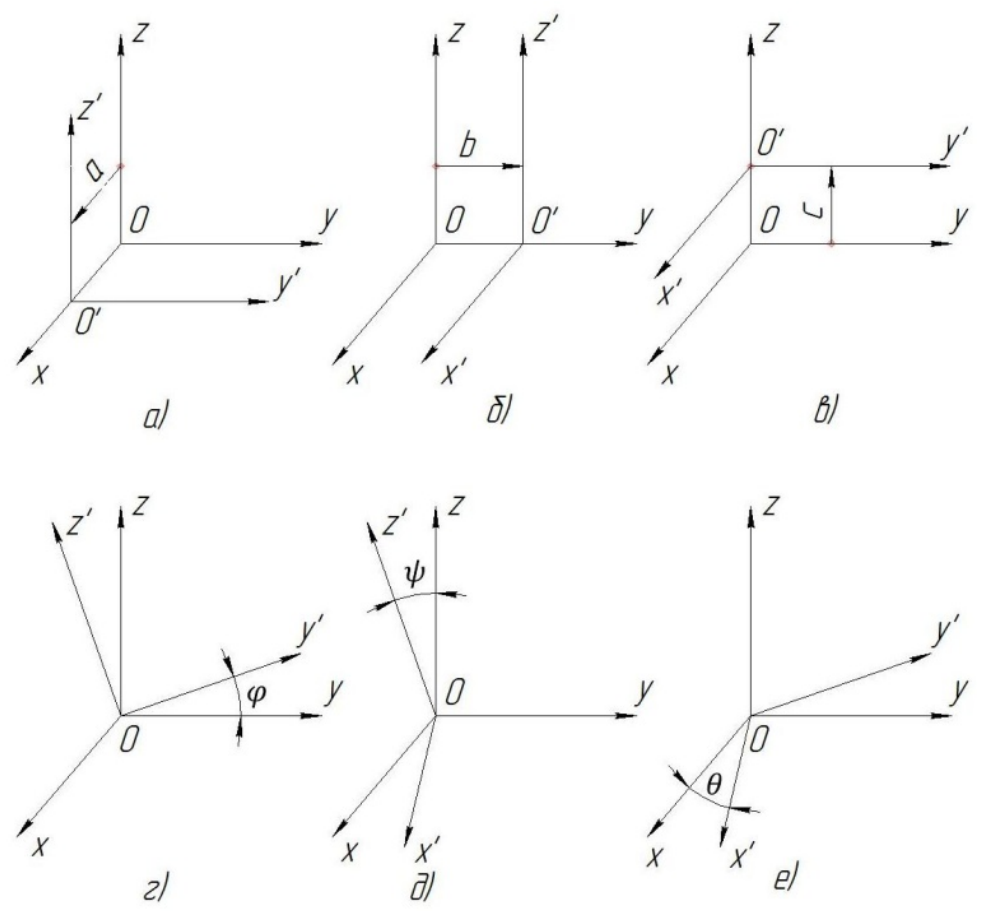

Puc. 1. Геометрична інтерпретація узагальненого переміщення твердого тіла; $a, \sigma, \varepsilon-$ поступальні переміщення уздовж осей $x, y, z$. $2, \partial, e-$ повороти навколо осей $x, y, z$

Матрицю $A$, яка входить в (1), можливо отримати по координатному коду формоутворюючої системи [5]. У кожному конкретному випадку шляхом перемноження певних матриць виду (2) можна отримати результуючу матрицю у відповідності з наявністю фактичних переміщень. Такий підхід ускладнює реалізацію методу на практиці, тому що в кожному випадку для отримання такої матриці потрібно визначити окремі матриці, що моделюють переміщення, а потім робити математичні операції - множення матриць. Значно ефективнішим може бути спосіб, коли застосовується універсальна матриця, придатна на всі можливі випадки для конкретного верстату.

У роботі [8] представлений варіант отримання такої матриці, яка заснована на узагальненні окремих випадків і враховує лінійні переміщення уздовж осей, обертання навколо осей i поступальні переміщення уздовж осей після поворотів. Результуюча матриці має вигляд 
де $a_{11}=\cos$ и $\cos ц ;$

$$
\begin{gathered}
A=A_{x_{3}} \cdot A_{y_{3}} \cdot A_{z_{3}} \cdot A_{\text {ц }} \cdot A_{x_{2}} \cdot A_{y_{2}} \cdot A_{z_{2}} \cdot A_{\text {Ш }} \cdot A_{x_{1}} \cdot A_{y_{1}} \cdot A_{z_{1}} \cdot A_{\text {и }} \cdot A_{x} \cdot A_{y} \cdot A_{z}= \\
\left(\begin{array}{llll}
a_{11} & a_{12} & a_{13} & a_{14} \\
a_{21} & a_{22} & a_{23} & a_{24} \\
a_{31} & a_{32} & a_{33} & a_{34} \\
a_{41} & a_{42} & a_{43} & a_{44}
\end{array}\right),
\end{gathered}
$$

$a_{12}=-\sin$ и $\cos ш ;$

$a_{13}=\sin \omega$

$a_{14}=a_{3}+a_{2}+\left(a_{1}+a \cos\right.$ и $\left.-b \sin И\right) \cos ш+\left(c_{1}+c\right) \sin ш ;$

$a_{21}=\sin$ и $\cos ц+\cos$ и $\sin ш \sin ц ;$

$a_{22}=\cos$ и $\cos ц-\sin$ и $\sin Ш \sin ц ;$

$a_{23}=-\cos ш \sin$ ц;

$a_{24}=b_{3}+\left(b_{2}+b_{1}+a \sin\right.$ и $+b \cos$ и $) \cos ц-\left(c_{2}-\left(c_{1}+c\right) \cos ш\right) \sin$ ц;

$a_{31}=\sin$ и $\sin ц-\cos$ и $\sin ш \cos ц ;$

$a_{32}=\cos$ и $\sin ц+\sin$ и $\sin ш \cos ц ;$

$a_{33}=\cos ш \cos$ ц;

$a_{34}=c_{3}+\left(b_{2}+b_{1}+a \sin\right.$ и $+b \cos$ и $) \sin ц+\left(c_{2}-\left(c_{1}+c\right) \cos ш\right) \cos ц ;$

$a_{41}=a_{42}=a_{43}=0$;

$a_{44}=1$.

В (3) матриці $A_{x_{3}}, A_{y_{3}}, A_{z_{3}}$ моделюють поступальний рух уздовж осей $X, Y, Z$ після повороту навколо осі $X$, матриці $A_{x_{2}}, A_{y_{2}}, A_{z_{2}}$ - після повороту навколо осі $Y$, а матриці $A_{x_{1}}, A_{y_{1}}$, $A_{z_{1}}$ - після повороту навколо осі $Z$. Аналогічно $a_{3}, b_{3}, c_{3}$ - величини поступальних переміщень уздовж координатних осей після повороту навколо осі $X, a_{2}, b_{2}, c_{2}$ - після повороту навколо осі $Y$, а $a_{1}, b_{1}, c_{1}$ - після повороту навколо осі $Z$.

При необхідності матриця (3) може бути перетворена в будь яку іншу, при відсутності яких небудь переміщень. Для цього достатньо прийняти $A_{0}=1$ і відповідні величини поступального руху $a, b, c$ і $a_{i}, b_{i}, c_{i}$ прийняти рівними 0.

Підставивши в (1) другий співмножник, який описує ріжучі кромки інструменту, можна отримати координати формоутворюючої поверхні при обробці на верстаті. Наприклад, при обробці деталі фрезою на верстаті з ЧПК (рис. 2) передбачаються лінійні переміщення вздовж осей $X, Y, Z$ і обертання інструменту навколо осі $Z$.

Матриці $A_{ц}, A_{ш}, A_{x_{3}}, A_{y_{3}}, A_{z_{3}}, A_{x_{2}}, A_{y_{2}}, A_{z_{2}} \quad$ будуть $\quad$ рівні $1, \quad$ а $\quad$ значення $a_{3}, b_{3}, c_{3}, a_{2}, b_{2}, c_{2}$, ш, ц - 0 . Таким чином матриця $A$ буде мати вигляд

$$
A=A_{x_{1}} A_{y_{1}} A_{z_{1}} A_{\text {и }} A_{x} A_{y} A_{z}=\left(\begin{array}{cccc}
\cos и & -\sin и & 0 & a_{1}+a \cos и-\sin и \\
\sin и & \cos и & 0 & b_{1}+a \sin и+b \cos и \\
0 & 0 & 1 & c_{1}+c \\
0 & 0 & 0 & 1
\end{array}\right) .
$$

Циліндрична (кінцева) фреза може бути записана виразом

$$
r_{\mathrm{L}}=\left(\begin{array}{c}
R \cos \sigma \\
R \sin \sigma \\
Z \\
1
\end{array}\right)
$$

Тоді формула (1) для даного випадку буде мати вигляд

$$
r_{0}=A \cdot r_{l}, \quad r_{0}=A r_{l}=\left(\begin{array}{c}
R(\cos \text { и } \cos \text { б }-\sin \text { и } \sin б)+a_{1}+a \cos \text { и }-b \sin \text { и } \\
R(\sin \text { и } \sin б+\cos \text { и } \sin б)+b_{1}+a \sin \text { и }+b \cos \text { и } \\
z+c_{1}+c \\
1
\end{array}\right) .
$$

Підставивши в (4) значення радіусу інструменту $R$, його довжину $Z$ і кут нахилу леза до поверхні циліндра фрези б, а також $a, b, c$ - величини поступальних переміщень уздовж координат $X, Y, Z, a_{1}, b_{1}, c_{1}$ - переміщення уздовж координат $X, Y, Z$ після повороту навколо осі $Z$ i кут повороту и навколо осі $Z$, отримаємо координати точок дотику леза інструменту і деталі під час обробки, тобто координати формованої поверхні. 


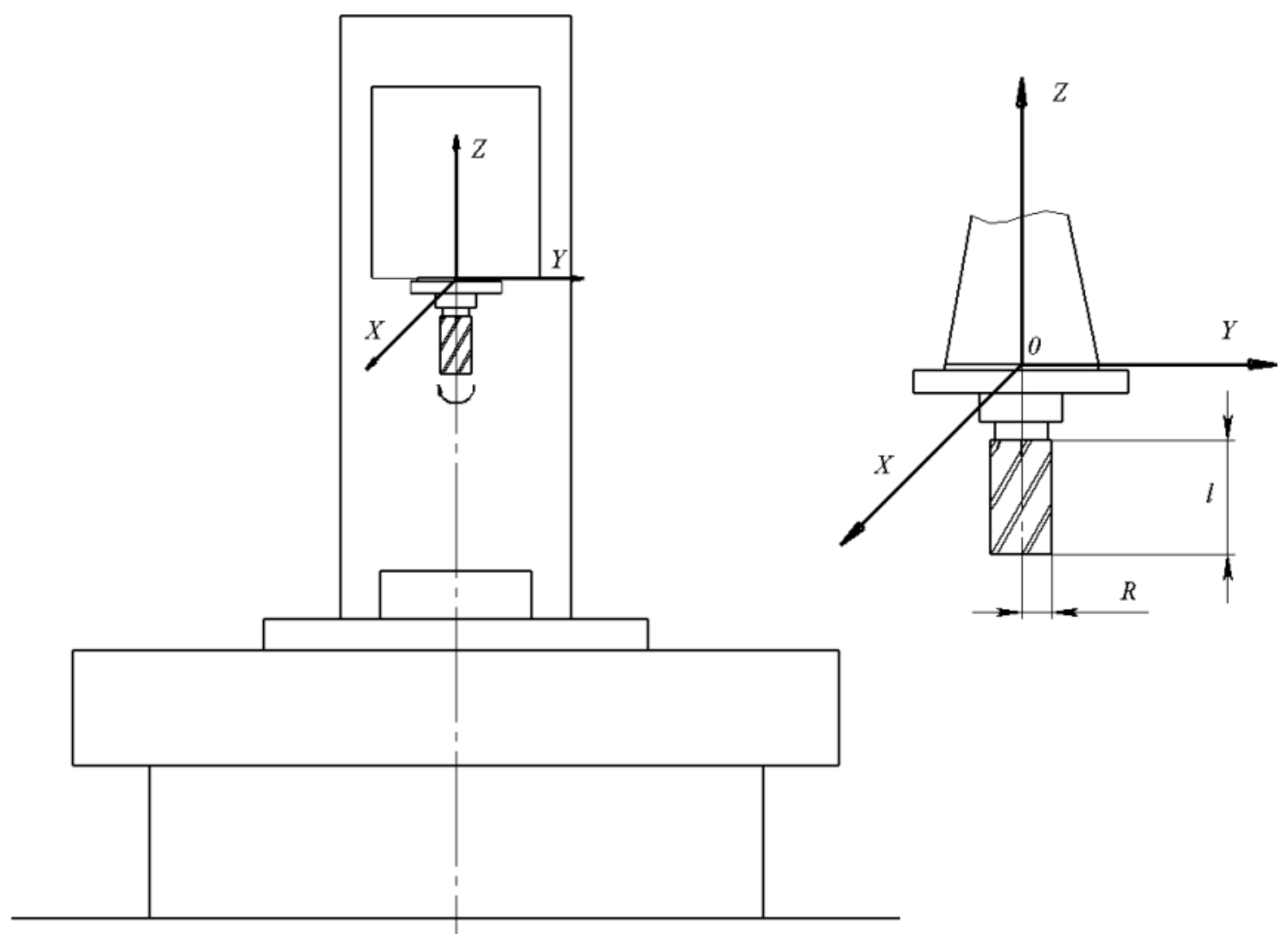

Рис. 2. Вид координатної системи вертикально фрезерного верстата з ЧПК і ріжучого інструменту

\section{Висновок}

Використовуючи такий підхід можна отримати координати точок формоутворюючих частин ріжучого інструменту при обробці деталі по керуючій програмі на верстаті з ЧПК. При наявности опису геометрії ріжучих інструментів на стадії розрахунку траєкторій руху, створюється можливість аналізу формування поверхонь на оброблюваних деталях. При необхідності пошуку ефективних варіантів розрахунку траєкторій, як для попередніх, так і остаточних технологічних переходів, створюється можливість до безпосередньої обробки моделювати процеси $з$ метою пошуку найкращого.

\section{Список використаної літератури}

1. Гжиров Р.И., Серебреницкий П.П. Программирование обработки на станках с ЧПУ: Справочник. Л.: Машиностроение. Ленинр. Отд-ние, 1990. 588 с.

2. Константинов М.Т. Расчет программ фрезерования на станках с ЧПУ. М.: Машиностроение, 1985. $165 \mathrm{c}$.

3. Молчанов Г.Н. Повышение эффективности обработки на станках с ЧПУ. М.: Машиностроение, 1979. $240 \mathrm{c.}$

4. Байков В.Д., Вашкевич С.Н. Решение траекторных задач в микропроцессорных системах ЧПУ/ Под ред. Б.Б.Смолова. Л.: Машиностроение, Ленингр. Отд-ние, 1986. 106 с.

5. Решетов Д.Н., Портман В.Т. Точность металлорежущих станков. М.: Машиностроение, 1986. $336 \mathrm{c}$.

6. Адаптивное управление станками / Под ред. Б.С.Балакшина: М.: Машиностроение, 1973. 688 с.

7. Коротков В.С., Завацкий В.Л. Контроль точности формообразования деталей на фрезерном станке с ЧПУ //Технология и организация производства. 1988. № 1. С. 23. 
8. Лигун А.А., Шумейко А.А., Коротков В.С. и Завацкий В.Л. Об универсальной матрице для описания формообразования поверхностей в трехмерном пространстве. К., 1988. 10 с. Деп. В УкрНИИНТИ 29.03.88. № 754.

\section{SIMULATION OF SURFACE FORMATION BY CUTTING TOOLS ON CNC MACHINES}

Korotkov V., Shumeiko A.

\section{Abstract}

In the process of metalworking on CNC machines there are errors, the formation of which is influenced by the actions of many factors, the action of which is very difficult to predict. Therefore, in practice there is often a need to correct the trajectory of the tool to eliminate inadmissible deviations in size. The solution of problems of forecasting of accuracy of processing at a stage of preparation of control programs is possible with use of modern methods of modeling of formation of surfaces of details at use of computer engineering.

For the mathematical description of the formation of parts, mathematical operations of multiplication of matrices are used, which model the translational motion along the $X, Y, Z$ axes, rotation around the axes, as well as the recording of the forming surfaces of the cutting tool. If necessary, the resulting matrix can be easily converted into any other, in the absence of any displacements.

This approach allows you to get the coordinates of the points of the forming parts of the cutting tool when machining a part on the control program on a CNC machine. If it is necessary to find effective variants of the trajectories of the shaping tools, it is possible to model the processing in order to find the best.

\section{References}

[1] Gjirov R.I., \& Serebrenitsky P.P. (1990). Programirovanie obrabotki na stankah s ChPU: Spravochnik [Programming of processing for NS-machines]. Leningrad: Mashinostroenie. Leningr. Otdelenie [the USSR].

[2] Konstantinov M.T. (1985). Raschet program freserovania na stankah s ChPU [Calculation of milling programs on CNC machines]. Moskva: Mashinostroenie [the USSR].

[3] Molchanjv G.N. (1979). Povishenie effectivnosti obrabotki na stankah s ChPU [Improving the efficiency of processing on CNC machines]. Moskva: Mashinostroenie [the USSR].

[4] Baikov V.D. \& Vashkevich S.N. (1986). Reshenie traektornyh sadash v microprocessornyh sistemah ChPU [Solving trajectory problems in microprocessor-based CNC systems]. Leningrad: Mashinostroenie. Leningr. Otdelenie [the USSR].

[5] Reshetov D.N. \& Portman V.T. (1986). Tochnost metallorezhushih stankov [Precision machine tools]. Moskva: Mashinostroenie [the USSR].

[6] Balakshin B.S. (1973). Adaptivnoe upravlenie stankami [Adaptive machine control](ed. By D.S.Balakshin). Moskva: Mashinostroenie [the USSR].

[7] Korotkov V.S. \& Zavazki V.L. (1988). Kontrol toshnosti formoobrazovania detaly na frezernom stanke c ChPU [Control of the accuracy of forming parts on a CNC milling machine]. Technologia I organizacia proizvodstva - Technology and organization of production, 1, 23 [the USSR].

[8] Ligu A.A., Shumeiko A.A., Korotkov V.S. \& Zavazki V.L. (1988). Ob universalnoi matrize dlia opisania formoobrazovania poverhnosty $\mathrm{v}$ trehmernom orostranstve [About a universal matrix for describing the shaping of surfaces in three-dimensional space]. Kyiv: UkrNIINTI 754, 10 [in Ukrainian]. 